\title{
One-year course of paediatric headache in children and adolescents aged 8-15 years
}

\author{
J Gaßmann, L Morris, M Heinrich \& B Kröner-Herwig \\ Georg-Elias-Müller-Institute of Psychology, Department of Clinical Psychology and Psychotherapy, University of Göttingen, Göttingen, \\ Germany
}

\section{Cephalalgia}

Gaßmann J, Morris L, Heinrich M \& Kröner-Herwig B. One-year course of paediatric headache in children and adolescents aged 8-15 years. Cephalalgia 2008; 28:1154-1162. London. ISSN 0333-1024

The aims of the present study were the assessment of headache (HA) prevalence in German children and adolescents in the second year of a 4-year longitudinal study and the analysis of headache status change from year 1 to year 2 . The original sample consisted of 8800 households with a child aged 7-14 years. A total of 4159 households responded in both year 1 and year 2, yielding 3984 valid parent questionnaires. Data regarding various aspects of the child's HA history and general health were gathered via mailed questionnaires from the parents. Of the households returning valid parent questionnaires at survey 2, 48.9\% reported their child to have experienced headaches during the previous 6 months (53\% at survey 1). Weekly HA was reported for $6.5 \%$ of the children, monthly or less frequent HA for $16.5 \%$ and $25.9 \%$, respectively. With regard to headache diagnosis, $55.0 \%$ of the children and adolescents with HA experienced tension-type HA (TTH) and $11.3 \%$ migraine with or without aura (M). For more than half of the children and adolescents with HA $(57.0 \%)$ the frequency of head pain remained stable over the period of 1 year (i.e. same frequency category in years 1 and 2). Improved and worsened HA status regarding frequency of occurrence was found in $22.3 \%$ and $20.7 \%$ of the subjects, respectively. Thus, there was no definite trend towards an increase of HA episodes over the course of 1 year regarding the individual child or adolescent. The most stable type of HA was TTH. $\square$ Children, headache, prevalence, population-based epidemiological study, change

Jennifer Gaßmann, Dipl. Psych., Georg-August-University Göttingen, Georg-Elias-Müller-Institute of Psychology, Department of Clinical Psychology and Psychotherapy, Gosslerstr. 14, 37073 Göttingen, Germany. E-mail jgassma2@uni-goettingen.de Received 20 November 2007, accepted 7 April 2008

\section{Introduction}

The rates of paediatric headache (HA) found in the literature range from $1.4 \%$ (1) to $97 \%$ (2) depending on the type of prevalence estimate reported (i.e. point, period or lifetime), the employed diagnostic criteria [Vahlquist (3), modified Vahlquist, or International Headache Society (IHS)] (4), the assessment method (e.g. questionnaire, interview), the type of sample studied (e.g. population-based, clinical) and other factors such as socioeconomic status $(5,6)$.
Research that has focused on frequent HA has been hampered by the lack of a binding definition of what is meant by 'frequent' or 'recurrent' (7-10). For example, 'recurrent' HA has been defined as HA occurring 'once a week or more' $(8,11)$ or 'more than once a year' (12). Similarly, 'frequent' HA has been defined as HA that is experienced 'more than once a month' (9) or 'at least weekly' (13). Other studies lack an explicit definition of what is termed 'recurrent headache' $(9,14)$. Taken together, these inconsistencies make it difficult to compare prevalence rates across studies. Indeed, the integration of 
Table 1 Persistence rates of headache (HA) in various studies

\begin{tabular}{|c|c|c|c|c|c|}
\hline Authors & Country & $\begin{array}{l}\text { Age of } \\
\text { sample (years) }\end{array}$ & $\begin{array}{l}\text { Follow-up } \\
\text { time (years) }\end{array}$ & Pain condition & $\begin{array}{l}\text { Persistence } \\
\text { rate }(\%)\end{array}$ \\
\hline Wang et al. (26) & Taiwan & $13-15$ & 1 & Migraine & 42 \\
\hline Larsson \& Sund (13) & Norway & $12-14$ & 1 & $\begin{array}{l}\text { Frequent HA (defined as at least } \\
\text { weekly pain) }\end{array}$ & 38 \\
\hline Brattberg $(30,60)$ & Sweden & $10-15$ & 2 & Question: 'Do you often have HA?' & 30 \\
\hline Metsähonkala et al. (73) & Finland & $8-9$ & 3 & Migraine & 63 \\
\hline \multirow[t]{3}{*}{ Camarda et al. (24) } & Italy & 17 & 5 & MoA & 56 \\
\hline & & & & MA & 11 \\
\hline & & & & $\mathrm{ncH}$ & 14 \\
\hline \multirow[t]{3}{*}{ Schmidt et al. (74) } & Germany & 8 & 5 & HA at least $3 \times / 6$ months & 73 \\
\hline & & 13 & & & 56 \\
\hline & & 8 & 10 & & 47 \\
\hline Virtanen et al. (9) & Finland & 6 & 6 & HA disturbing daily activities & 41 \\
\hline Sillanpää (51) & Finland & 7 & 7 & Migraine & 41 \\
\hline
\end{tabular}

MA, migraine with aura; MoA, migraine without aura; ncH, non-classifiable headache.

research results is only possible by regarding prevalence rates for concrete frequencies such as 'at least once a month'. Using this approach, results from the literature indicate monthly HA to occur in $9 \%$ (15) to $65 \%$ (16) of children and adolescents, whereas rates for weekly HA range from 3\% (15) to $40 \%$ (17).

As regards type of paediatric headache, prevalence rates ranging from 1 to $19 \%$ have been reported for migraine $(\mathrm{M})$, with an average value of $4-6 \%(14,18-22)$. The rates of tension-type HA (TTH) found in the literature vary from $0.9 \%$ (19) to $72.8 \%$ (23). Thus, research indicates the latter to be the more widespread form of $\mathrm{HA}$ in children and adolescents.

The stability or persistence of HA can be determined only in longitudinal studies. Only a few such studies have been carried out to date, the majority of which have focused on the subgroup of children with $M(1,22,24-26)$. An overview of epidemiological findings regarding HA persistence is given in Table 1.

Information regarding changes in paediatric HA characteristics over time has most often been gathered from children and adolescents presenting at HA clinics $(27,28)$. The most frequent transition that has been found is that from M to TTH (28).

Altogether, research indicates that paediatric HA is not a transient complaint. Although the stability of paediatric HA has also been investigated in school- or community-based studies, only a few of these have examined stability in a short-term perspective $(13,26,29,30)$.

This is the first German longitudinal study to present population-based data on paediatric HA with retrospective recall of headache. In addition, the research was not limited to either HA frequency or diagnosis, but encompassed both. The objective was to provide detailed information about the distribution and characteristics of paediatric HA as reported in year 2 of a longitudinal study (see Kröner-Herwig et al. (31) for cross-sectional results from year 1). A further aim was to determine how the distribution and characteristics of HA changed from year 1 to year 2 in relation to age and gender.

We analysed the following aspects:

1. The distribution of HA frequency according to age and gender (year 2)

2. The distribution of types of HA according to age and gender (year 2)

3. Changes in HA frequency (unchanged, improved, worsened) from year 1 to year 2

4. Changes in types of HA from year 1 to year 2

\section{Methods}

\section{Sample and procedure}

The present research has its origin in the Children, Adolescents \& Headache Study, a longitudinal postal survey with four annual waves focusing on paediatric headache, health and potentially related psychosocial variables. The sample was randomly selected from the community registries of four districts in southern Lower Saxony and the city of Hannover, thus including both urban and rural communities. The first two waves were the focus of the present research. Wave 1 took place between October 2003 and January 2004 (in the following: 


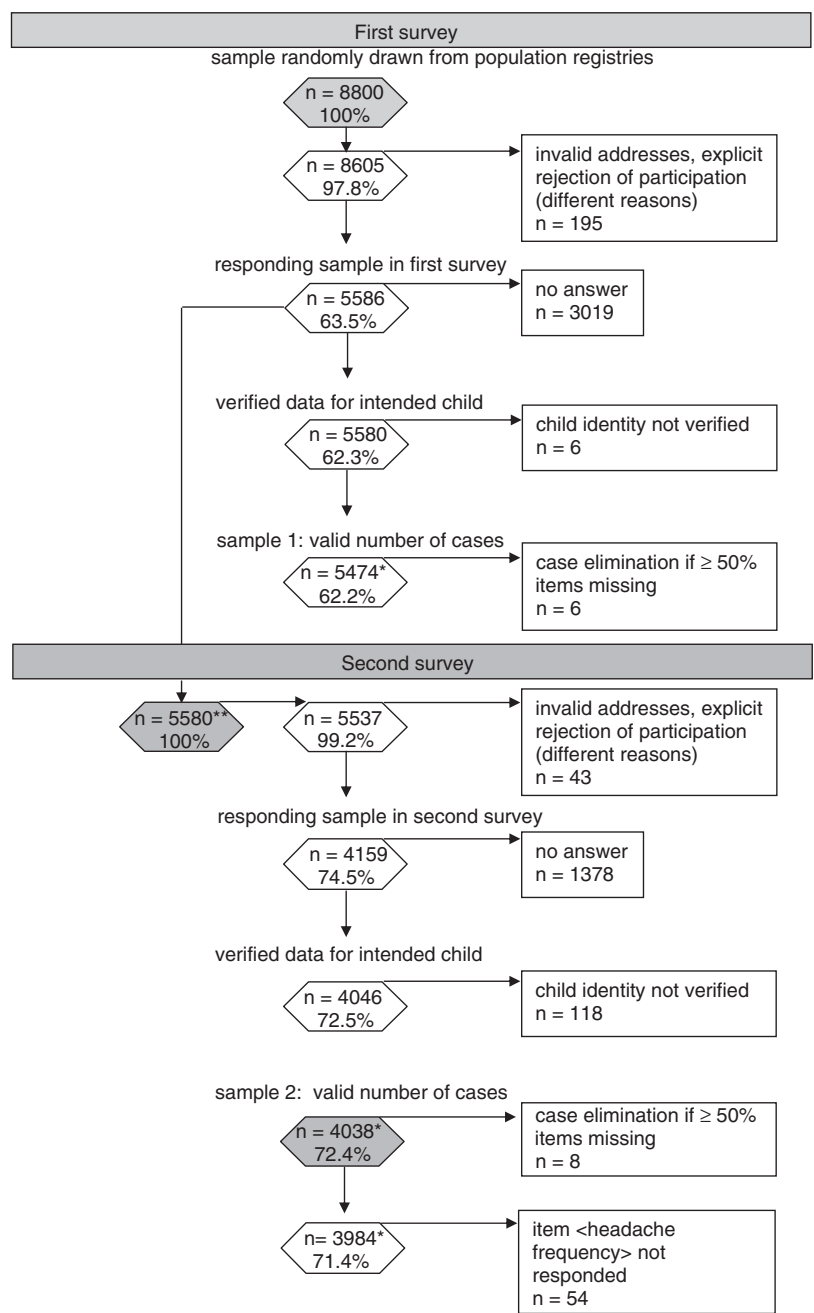

Figure 1 Study sample (parent questionnaire). *The size of $n$ varies between items because of missing item-specific data. ${ }^{* *}$ Number of families contacted in the second survey (reduced sample size because of explicit rejection of participation).

2003), wave 2 from October 2004 to January 2005 (in the following: 2004). Originally, 8800 families were contacted.

Figure 1 shows the number of participants, excluded cases and the valid number of cases which could be included in our analyses. At the time of the second wave, the children and adolescents had a mean age of 11.25 years (S.D. \pm 2.28 years; range 8-15 years).

Parent questionnaires were sent to all households. Child questionnaires were sent to households with a child aged $\geq 9$ years. Parent questionnaires are the focus of the present research, therefore the results represent the parents' perceptions of the children's HA. This approach has been utilized in a number of other studies $(1,8,9$, 14, 32). For more detailed information on study conduction, questionnaire development and results from wave 1, see Kröner-Herwig et al. (31).

\section{Definitions and operationalizations regarding headache}

In both wave 1 and wave 2 of the survey HA frequency was categorized into four groups. ' $\mathrm{No}^{\prime}$ HA means that the parents reported that their child had not experienced HA in the last 6 months. HA was categorized as 'less than monthly' if they reported a maximum of five HA episodes in the last 6 months. HA frequency was defined as 'monthly' if the child had experienced HA at least once a month and 'weekly' if HA had occurred at least once a week. This categorization was chosen because of its clinical relevance and its agreement with categorizations utilized in other studies $(6,33,34)$. The classification of type of HA [TTH, migraine with or without aura (M) and non-classifiable HA $(\mathrm{ncH})]$ was based on the criteria of the Subcommittee of the IHS (2004) (4). The ICHD-II criteria B-D were taken into account. Separate questions were formulated with different response options related to the duration of the attack, headache characteristics and potential aura symptoms (for detailed information on headache characteristics and distributions in different diagnoses see Kröner-Herwig et al. (31)). Criterion A (number attacks $\geq 5$ ) and criterion E (HA not attributed to another disorder) were not assessed, a modification that has also been utilized in previous research (26).

\section{Statistical analysis}

The annual incidence was calculated using newly diagnosed cases of HA per 100 children who were reported to have been HA-free in wave 1 .

Univariate associations between categorical variables were evaluated with the $\chi^{2}$ test to test for significance of the association of frequency data. Furthermore, it was used to estimate whether the distribution among categories of one variable was independent of their distribution among categories of the other.

All statistical analyses were performed using SPSS software, version 12.0 (SPSS Inc., Chicago, IL, USA). The level of significance was set at $P \leq 0.01$. 


\section{Results}

\section{Headache frequency}

Of the households returning the parental questionnaire, $48.9 \%$ reported their child to have experienced HA during the past 6 months $(54.2 \%$ girls, $45.8 \%$ boys).

Weekly HA was reported in $6.5 \%$ of the children, monthly or less frequent HA for 16.5 and $25.9 \%$, respectively.

HA percentages increased significantly with age (Fig. 2). The figure shows all children and adolescents; however, regarding only those that reported HA, we found the following: although having experienced $\mathrm{HA}$ at least once in the past 6 months was reported in $38.2 \%$ of the 8 -year-olds, this was the case for $54.6 \%$ of the 15-year-olds $\left(\chi^{2}(7)=40.56\right.$, $P=0.000$ ). Similarly, weekly HA occurred in $8.2 \%$ of the 8 -year-olds, but in $16.3 \%$ of the 15 -year-olds.

Girls were more likely to experience frequent HA than boys, especially monthly or weekly episodes (frequency $\times$ gender: $\chi^{2}(2)=30.48, P=0.000$ ).

\section{Type of headache}

As regards the total sample, the 6-month prevalence was highest for TTH (27.1\%) and lowest for migraine $(5.6 \%)$. For nearly one-sixth of the children it was not possible to classify HA on the basis of parent response (ncH 16.6\%).

HA diagnosis changed significantly with age (Fig. 3). The proportion of children with TTH dropped from $57 \%$ among 8-year-olds to $45.6 \%$ among 15 -year-olds $\left(\chi^{2}(7)=16.99, P=0.017\right)$. The proportion of $\mathrm{M}$, on the other hand, increased with age from 10 to $17.1 \%\left(\chi^{2}(7)=18.82, P=0.009\right)$.

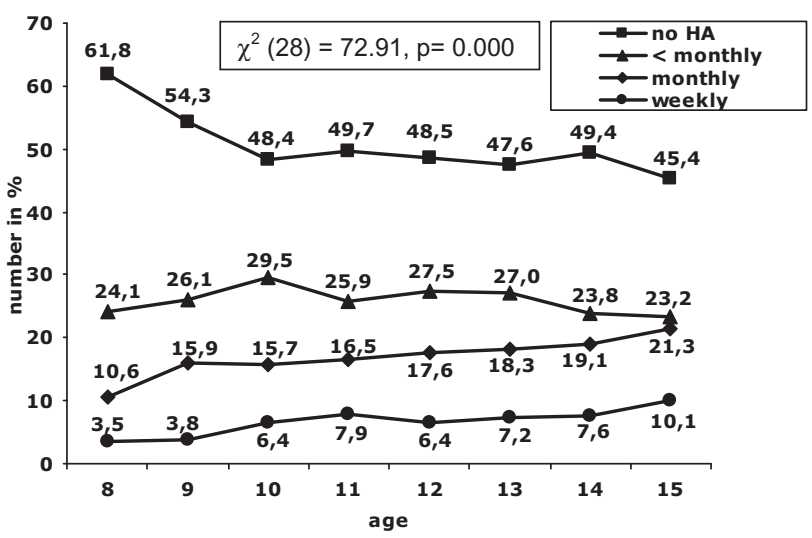

Figure 2 Frequency of headache $(\mathrm{HA}) \times$ age $(n=3984)$.
Type of HA and frequency of occurrence were related: HA frequency was significantly higher in children with $M$ than in those with TTH (e.g. weekly $\mathrm{HA}, 21.5 \%$ for $\mathrm{M}$ vs. $10.5 \%$ for $\mathrm{TTH} ; \chi^{2}$ (4) $=35.86, P=0.000$ ).

There was no significant effect of gender on type of HA $\left(\chi^{2}(2)=2.04, P=0.36\right)$.

\section{Changes in headache frequency}

A total of 3945 questionnaires were analysed regarding changes in HA frequency from wave 1 to wave 2 . HA was newly experienced by about onequarter $(25.1 \%)$ of the children and adolescents with no HA in wave 1 (annual incidence). On the other hand, $15.2 \%$ of the children and adolescents with $\mathrm{HA}$ in wave 1 were HA-free in the 6 months prior to wave 2 assessment.

Of the children and adolescents with HA in wave 1 , for $57 \%$ the reported category of HA frequency remained unchanged in wave 2, for $22.4 \%$ an improvement was reported (i.e. a change to a lower HA frequency category) and for $20.6 \%$ a worsening (i.e. a change to a higher frequency category). Nevertheless, the overall percentage of children and adolescents experiencing monthly HA was virtually the same at both assessments (wave 1, 16.9\%; wave $2,16.5 \%$ ). Table 2 shows the overall changes of HA frequency from 2003 to 2004.

Changes in HA frequency depending on age are shown in Fig. 4. Obviously, more children in the younger age group (8-11) experienced a worsening regarding HA frequency from wave 1 to wave 2 than in the older age group $\left(\chi^{2} \quad(2)=50.74\right.$, $P=0.000)$.

A significant, but small difference was found between girls and boys regarding the proportion of

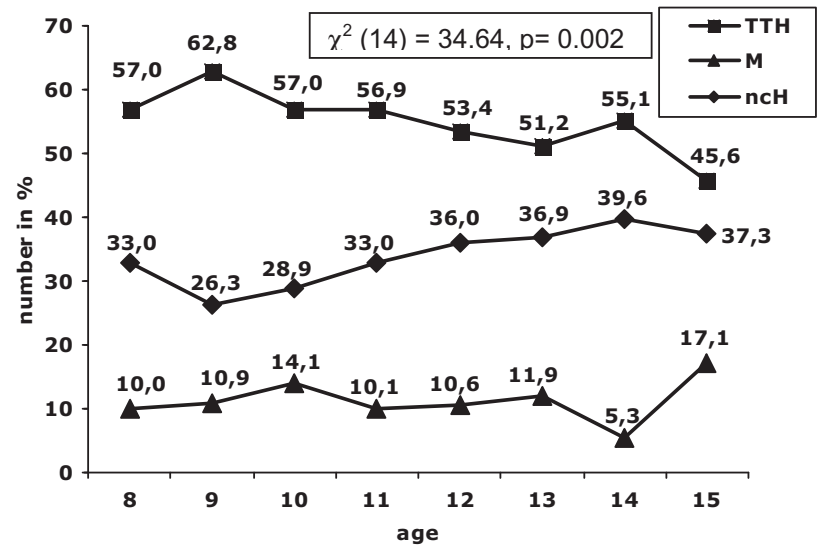

Figure 3 Type of headache $(\mathrm{HA}) \times$ age $(n=1970)$. TTH, tension-type $\mathrm{HA}$; $\mathrm{M}$, migraine; $\mathrm{ncH}$, non-classifiable $\mathrm{HA}$. 
Table 2 Changes in headache (HA) frequency from wave 1 to wave 2

\begin{tabular}{|c|c|c|c|c|c|}
\hline \multirow[b]{3}{*}{2003} & \multicolumn{5}{|l|}{2004} \\
\hline & no HA & $<1 /$ month & $\geq 1 /$ month & $\geq 1$ /week & Total \\
\hline & $n(\%)$ & $n(\%)$ & $n(\%)$ & $n(\%)$ & $n(\%)$ \\
\hline No HA & 1415 (74.9) & 342 (18.1) & $96(5.1)$ & $35(1.9)$ & $1888(100)$ \\
\hline$<1 /$ month & 449 (38.3) & $472(40.3)$ & $208(17.7)$ & $43(3.7)$ & $1172(100)$ \\
\hline$\geq 1 /$ month & 114 (17.2) & $180(27.2)$ & $276(41.8)$ & $91(13.8)$ & $661(100)$ \\
\hline$\geq 1$ /week & 35 (15.6) & $28(12.5)$ & 76 (33.9) & 85 (37.9) & $224(100)$ \\
\hline Total & $2013(51.0)$ & $1022(25.9)$ & 656 (16.6) & $254(6.4)$ & 3945 (100) \\
\hline
\end{tabular}

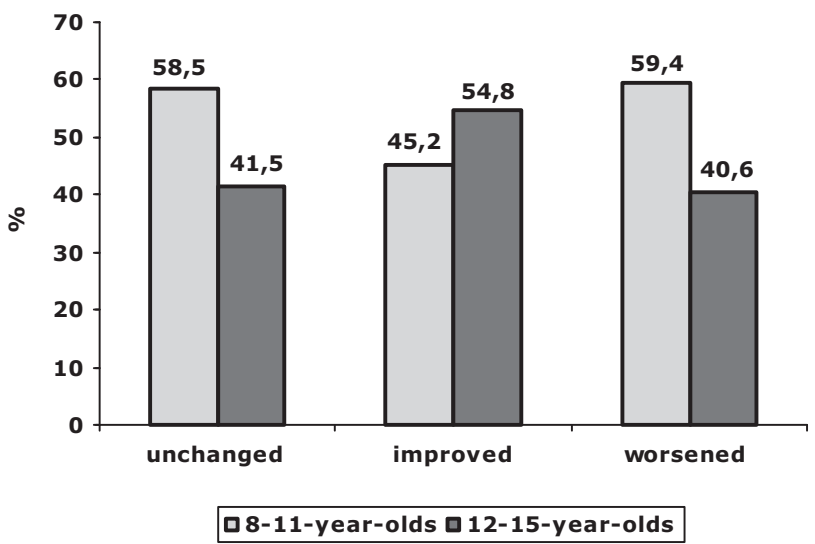

Figure 4 One-year course of headache frequency from wave 1 to 2 .

improved (boys 24.5\%, girls 20.2\%), unchanged (boys $56.3 \%$, girls $57.7 \%$ ) or worsened (boys $19.2 \%$, girls $22.1 \%)$ status of HA frequency $\left(\chi^{2}(2)=12.46\right.$, $P=0.002)$.

\section{Changes in type of headache}

Over half $(54.4 \%)$ of the children and adolescents with headache in wave 1 were reported to have the same type of $\mathrm{HA}$ in wave 2, i.e. their HA diagnosis remained unchanged. Of all participants with HA, $23 \%$ with TTH still had the same kind of HA in wave 2; for $M$ this was $6.9 \%\left(\chi^{2}(4)=293.35\right.$, $P=0.000$ ) (see Fig. 5). About one-third (29.4\%) of children with TTH in wave 1 were HA-free 1 year later; for children with $\mathrm{M}$ this figure was only $10.5 \%$. The prevalence for $M$ changed significantly from wave 1 to wave $2\left(2003,15.7 \% ; 2004,13.4 \% ; \chi^{2}\right.$ $(1)=530.79, P=0.000)$. This was also the case for TTH $\left(33.6 \%\right.$ and $51.5 \%$, respectively; $\chi^{2}(1)=156.36$, $P=0.000)$.

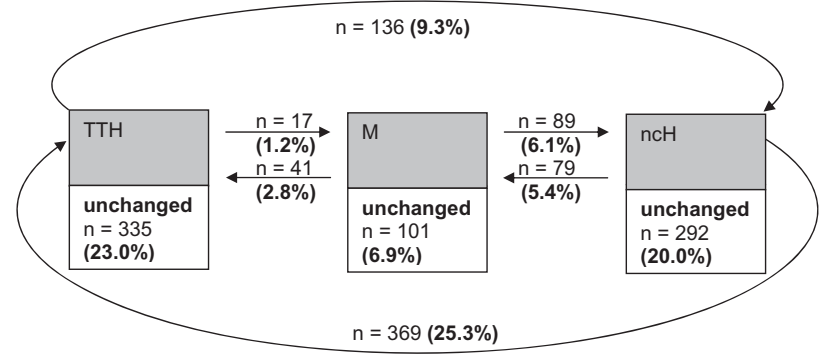

Figure 5 Changes in headache diagnosis from 2003 to 2004 $(n=1459)$. TTH, tension-type HA; M, migraine; $\mathrm{ncH}$, non-classifiable HA.

\section{Discussion}

About $49 \%$ of German children aged 8-15 years were found to have experienced HA at least once in a period of 6 months. This rate is within the range of prevalence rates reported for German children and adolescents $(35,36)$ and is also comparable to those found in international studies $(6,12,30,34$, 37-39).

\section{Headache frequency related to age and gender}

In published population-based longitudinal studies in school children using self-report questionnaires, percentages of children with weekly HA range from about $7 \%$ (40) to $54 \%$ (41). In the present study, weekly HA was reported in $6.5 \%$ of the children and adolescents, with a maximum prevalence of $13.3 \%$ in 15-year-old girls. This is a much lower rate than other studies have reported (from about 22\% (6) up to $30 \%(16,42,43))$. This divergence may be due to the use of different sources of information: whereas children's self-report data were analysed in the latter studies, the present study used parental questionnaires. Since child questionnaires were employed in the present study of children 
aged $\geq 9$ years, it was possible to determine whether prevalence rates varied depending on the informant. While a prevalence rate for weekly headache of $7.6 \%$ was calculated on the basis of parent report for 9-15-year-olds, the self-reported prevalence of $17.3 \%$ was much higher, which seems to indicate an underestimation of HA occurrence by the parents. Evidence of parental underreporting of children's HA has also been documented by other authors $(36,44,45)$. However, in this study we used parents' data in order to provide information also for younger children (8-year-olds), who did not complete a questionnaire.

The prevalence of monthly HA in the present sample was $16.5 \%$. This prevalence rate is also relatively low in comparison with international studies (about 23\% (46) up to 35\% (32)) regarding similar age groups and using similar methods (questionnaire survey). However, as there is evidence that the prevalence of HA has increased in past decades $(15,42,47)$, higher prevalence rates for weekly and monthly HA were to be expected.

There was a marked increase of HA occurrence over the age range, with $38.2 \%$ among 8 -year-olds and $54.6 \%$ among 15 -year-olds, which is in line with previous studies $(9,38,48,49)$. This is also the case regarding gender differences, with more girls than boys experiencing HA $(38,39,42,44,48-52)$.

\section{Type of headache related to age and gender}

The overall prevalence of $\mathrm{M}$ (using a modified version of the IHS criteria from 2004) was about $6 \%$ in our sample, the prevalence of TTH $27 \%$. These rates are in line with other recent international cross-sectional studies (e.g. 12, 39, 52), but much lower than those reported in the large-scale German study by Pothmann et al. (49). As mentioned above, a possible explanation for this divergence is the use of different sources of information (parent vs. child) and the respective assessment periods (6 months vs. life-time). Nevertheless, our results are similar to numerous findings indicating percentages $<10 \%$ (e.g. 1, 18, 22, 26, 50, 53-56). Our findings also agree with a large number of studies reporting TTH to be more prevalent than $M(23,38,39,52,55)$. Present data show that the proportion of HA-afflicted children with TTH decreases significantly with age, whereas the proportion of children with $M$ increases with age. Results discordant with our findings have been reported for German (49) and Turkish (12) children and adolescents. Therefore, in the face of these contradictory results, further research is necessary before any conclusions regarding the relationship between TTH and age can be drawn.

As was also the case with HA frequency, two conclusions can be drawn regarding age and gender interactions and type of HA: girls experience $M$ more often than boys, and these differences increase significantly with age. The prevalence for $\mathrm{M}$ among girls at age 15 was nearly twice that for boys.

\section{Changes in headache frequency}

Only a few studies have examined stability and changes of HA frequency in paediatric samples. The estimated overall 6-month incidence of about $25 \%$ in our study was higher than that of $13 \%$ reported by Laurell et al. (57), but similar to that reported for children at school entry (29\%) (58).

In our population-based sample about $15 \%$ of those with $\mathrm{HA}$ in wave 1 were HA-free 1 year later. Paediatric HA studies using community- and school-based samples have documented rates of children and adolescents becoming HA-free after a time span of 6 years ranging from 9\% (of Finnish children aged 6) (9) to 60\% (of Swedish 7-15-yearolds) (1).

In the present sample, $37 \%$ of children and adolescents reported HA in both waves. Rates of HA stability reported in the literature range from about $4 \%$ (4-year follow-up for 7-year-old English children) (59) to $79 \%$ (after 3 years, Swedish children aged 7-15 years) (57) in population-based studies. HA stability seems to be higher among girls than boys and also to increase with age $(13,60)$. This was also seen in our sample. HA frequency remained unchanged or worsened (wave 1 to wave 2) significantly more often among girls than boys. Our results fit well into the reported range of $30-40 \%$ (13, 60-63).

In the present sample the HA frequency category that exhibited the greatest stability was monthly HA.

Almost half of the children with weekly HA in wave 1 showed improvement (i.e. reduction of frequency category) in wave 2 . On the other hand, approximately three-quarters of children with monthly $\mathrm{HA}$ in wave 1 experienced a worsening 1 year later (i.e. experienced more frequent HA). The improvements found for children with weekly HA resemble results reported by Laimi et al. (64). However, these researchers found a worsening of HA frequency in only about one-third of their 
sample (64). We thus found a much higher rate of subjects who developed more frequent HA.

\section{Changes in type of headache}

The course of a specific type of HA in children has been most intensively investigated for $\mathrm{M}$ in clinicbased samples, although research on population- or school-based samples focusing on changes of different types of HA has been published recently (24, $41,57,65-67)$. Only a few follow-up studies have described the course of TTH over time, again mainly focused on paediatric patients $(28,68-72)$. Compared with other data, we found a slightly higher incidence for TTH, but a lower one for M (57). According to our results, TTH is more likely to remit than $\mathrm{M}(29.4 \%$ vs. $10.5 \%)$ after 1 year. Previous studies that examined the outcome of TTH and $\mathrm{M}$ in a sample from the general population have reported that $23 \%$ (57) to $27 \%$ (9) subjects with TTH and $15 \%(67)$ to $51 \%$ (1) of $\mathrm{M}$ sufferers become HA-free. Corresponding figures for clinic-based studies seem to be somewhat higher, with TTH being more likely to remit than $M(27,28,68,71)$. One explanation could be that children receiving treatment tend to recover. We actually inquired in wave 2 whether the parents had visited a physician in the last year with their child because of the child's headache (thus exactly the observation period in question). However, no consistent pattern emerged, so that an interpretation of these findings does not contribute to an understanding of changes in HA status.

Unexpectedly, only about $4 \%$ of children with TTH in wave 1 had $M$ in wave 2 , in contrast with results from other population-based samples indicating changes from TTH to $\mathrm{M}$ and vice versa to range from about 20 to $40 \%(57,65-67)$. The development in the other direction (from $\mathrm{M}$ changed to TTH) was found in about $8 \%$ of the sample. This result is more comparable to some previous published data (24), but nevertheless much lower than previous findings (57). One possible explanation for these discrepancies could be the different age ranges of the studied populations and the length of follow-up conducted by the other authors.

Altogether, research indicates that paediatric HA is not a transient complaint, even with regard to a relatively short time span of 1 year. Especially frequent HA appears to carry with it a high risk of becoming an enduring health condition. The identification of prognostic factors predicting the course of HA over time is one of our future objectives in the analysis of our longitudinal data.

\section{Strengths and limitations}

One strength of our study is the use of a large, representative sample that was randomly selected from urban and rural populations. This should enhance reliability and generalizability of the findings.

The response rate of $47.3 \%$ related to the original sample addressed in wave 1 is comparable to response rates achieved in other studies $(22,24,59)$ that did not rely on school-based surveys.

A possible limitation of the study is the presence of selection bias due to non-response of a specific group in wave 2 . We found that parents whose child had HA or those who had HA themselves were more likely to respond than parents who were HA-free or whose children were HA-free. This should result in an overestimation of the prevalence of paediatric HA. However, overestimation is not confirmed when comparing the rates for overall HA prevalence in waves 1 and 2 (overall HA 53 and $49 \%$, respectively). Furthermore, most of our figures regarding prevalences are lower than in other studies.

In our study the type of HA was diagnosed by means of a questionnaire survey rather than an interview. It may be argued that a valid diagnosis of type of HA can be arrived at only in an expert interview, since the criteria for the different diagnoses are rather complex. However, we decided to accept this possible limitation in order to gather representative data from a large sample. We utilized a modified version of the IHS criteria (4): we chose to forgo assessment of the A criterion (for migraine 'more than 5 attacks in lifetime', for TTH 'at least ten episodes'), because we considered it to be too difficult for parents to respond accurately. In addition, we did not explicitly exclude HA associated with infections or other diseases (criterion E). These modified, and therefore slightly more liberal criteria, may have led to overestimation of prevalence rates.

\section{Acknowledgement}

This research project was supported by a grant from the German Ministry of Education and Research as part of the German Headache Consortium.

\section{References}

1 Bille B. Migraine in school children-a study of the incidence and short-term prognosis, and a clinical, psychological and electroencephalographic comparison 
between children with migraine and matched controls. Acta Paediatr Scand 1962; 51 (Suppl. 136):1-151.

2 Bandell-Hoekstra IE, Abu-Saad HH, Passchier J, Frederiks CM, Feron FJ, Knipschild P. Prevalence and characteristics of headache in Dutch schoolchildren. Eur J Pain 2001; 5:145-53.

3 Vahlquist B. Migraine in children. Int Arch Allergy Appl Immunol 1955; 7:348-55.

4 Headache Classification Committee of the International Headache Society. The International Classification of Headache Disorders, 2nd edition. Cephalalgia 2004; 24 (Suppl. 1):9-160.

5 McGrath PA. Headache in children: the nature of the problem. In: McGrath PA, Hillier LM, eds. The child with headache: diagnosis and treatment. Seattle, WA: IASP Press 2001:1-27.

6 Kristjánsdóttir G, Wahlberg V. Sociodemographic differences in the prevalence of self-reported headache in Icelandic school-children. Headache 1993; 33:381-5.

7 Zuckerman B, Stevenson J, Bailey V. Stomachaches and headaches in a community sample of preschool children. Pediatrics 1987; 79:677-82.

8 Linna S-L, Moilanen I, Keistinen H. Prevalence of psychosomatic symptoms in children. Psychother Psychosom 1991; 56:85-7.

9 Virtanen R, Aromaa M, Rautava P, Metsahonkala L, Anttila P, Helenius $\mathrm{H}$ et al. Changes in headache prevalence between pre-school and pre-pubertal ages. Cephalalgia 2002; 22:179-85.

10 Gordon KE, Dooley JM, Wood EP. Self-reported headache frequency and features associated with frequent headaches in Canadian young adolescents. Headache 2004; 44:555-61.

11 Egermark-Eriksson I. Prevalence of headache in Swedish schoolchildren. A questionnaire survey. Acta Paediatr Scand 1982; 71:135-40.

12 Karli N, Akis N, Zarifoglu M, Akgöz S, Irgil E, Ayvacioglu $\mathrm{U}$ et al. Headache prevalence in adolescents aged 12 to 17: a student-based epidemiological study in Bursa. Headache 2006; 46:649-55.

13 Larsson B, Sund AM. One-year incidence, course, and outcome predictors of frequent headaches among early adolescents. Headache 2005; 45:684-91.

14 Shivpuri D, Rajesh MS, Jain D. Prevalence and characteristics of migraine among adolescents: a questionnaire survey. Indian Pediatr 2003; 40:665-9.

15 Sillanpää M, Anttila P. Increasing prevalence of headache in 7-year-old schoolchildren. Headache 1996; 36:46670.

16 Virtanen R, Aromaa M, Koskenvuo M, Sillanpää M, Pulkkinen L, Metsähonkala L et al. Externalizing problem behaviors and headache: a follow-up study of adolescent Finnish twins. Pediatrics 2004; 114:981-7.

17 White KS, Farrell AD. Anxiety and psychosocial stress as predictors of headache and abdominal pain in urban early adolescents. J Pediatr Psychol 2005; 31:582-96.

18 Raieli V, Raimondo D, Cammalleri R, Camarda R. Migraine headaches in adolescents: a student populationbased study in Monreale. Cephalagia 1995; 15:5-12.

19 Abu-Arafeh I, Russell G. Prevalence of headache and migraine in schoolchildren. BMJ 1994; 309:765-9.
20 Bille B. Migraine in childhood and its prognosis Cephalalgia 1981; 1:71-5.

21 Linet MS, Stewart WF, Celentano DD, Ziegler D, Sprecher M. An epidemiologic study of headache among adolescents and young adults. J Am Med Assoc 1989; 261:221116

22 Sillanpää M. Changes in the prevalence of migraine and other headaches during the first seven school years. Headache 1983; 23:15-19.

23 Barea LM, Tannhauser M, Rotta NT. An epidemiologic study of headache among children and adolescents of southern Brazil. Cephalalgia 1996; 16:545-9.

24 Camarda R, Monastero R, Santangelo G, Raimondo D, Puma D, Pipia C et al. Migraine headaches in adolescents: a five-year follow-up study. Headache 2002; 42:1000-5.

25 Bille B. A 40-year follow-up of school children with migraine. Cephalalgia 1997; 17:487-91.

26 Wang SJ, Fuh JL, Juang KD, Lu SR. Rising prevalence of migraine in Taiwanese adolescents aged 13-15 years. Cephalalgia 2005; 25:433-8.

27 Guidetti V, Galli F. Evolution of headache in childhood and adolescence: an 8-year follow-up. Cephalalgia 1998; 18:449-54.

28 Dooley J, Bagnell A. The prognosis and the treatment of headaches in children-a ten year follow-up. Can J Neurol Sci 1995; 22:47-9.

29 Brattberg G. Do pain problems in young school children persist into early adulthood? A 13-year follow-up. Eur J Pain 2004; 8:187-99.

30 Brattberg G. The incidence of back pain and headache among Swedish school children. Qual Life Res 1994; 3 (Suppl. 1):27-31.

31 Kröner-Herwig B, Heinrich M, Morris L. Headache in German children and adolescents: a population-based epidemiological study. Cephalalgia 2007; 27:519-27.

32 Waldie KE. Childhood headache, stress in adolescence, and primary headache in young adulthood: a longitudinal cohort study. Headache 2001; 41:1-10.

33 King NJ, Sharpley CF. Headache activity in children and adolescents. J Paediatr Child Health 1990; 26:50-4.

34 Carlsson J. Prevalence of headache in schoolchildren: relation to family and school factors. Acta Paediatr 1996; 85:692-6.

35 Kolip P, Nordlohne E, Hurrelmann K. Der Jugendgesundheitssurvey 1993. In: Kolip P, Hurrelmann K, Schnabel P-E, eds. Jugend und Gesundheit. Weinheim: Juventa 1995:25-48.

36 Ostkirchen GG, Andler F, Hammer F, Pöhler KD, SnyderSchendel E, Werner NK et al. Prevalences of primary headache symptoms at school-entry: a populationbased epidemiological survey of preschool children in Germany. J Headache Pain 2006; 7:331-40.

37 Anttila P, Metsahonkala L, Aromaa M, Sourander A, Salminen J, Helenius $\mathrm{H}$ et al. Determinants of tensiontype headache in children. Cephalalgia 2002; 22:401-8.

38 Laurell K, Larsson B, Eeg-Olofsson O. Prevalence of headache in Swedish schoolchildren, with a focus on tension-type headache. Cephalalgia 2004; 24:380-8.

39 Özge A, Bugdayci R, Sasmaz T, Kaleagasi H, Kurt O, Karakelle $\mathrm{A}$ et al. The sensitivity and specificity of the case definition criteria in diagnosis of headache: a 
school-based epidemiological study of 5562 children in Mersin. Cephalalgia 2003; 23:138-45.

40 Sillanpää M. Prevalence of migraine and other headache in Finnish children starting school. Headache 1976; 15:288-90.

41 Spierings EL, Schellekens JA. Causes of headache in high school students. Headache Q 1991; 2:225-8.

42 Rhee $\mathrm{H}$. Prevalence and predictors of headaches in US adolescents. Headache 2000; 40:528-38.

43 Dooley JM, Gordon KE, Wood EP. Self-reported headache frequency in Canadian adolescents: validation and follow-up. Headache 2005; 45:127-31.

44 Groholt EK, Stigum H, Nordhagen R, Kohler L. Recurrent pain in children, socio-economic factors and accumulation in families. Eur J Epidemiol 2003; 18:965-75.

45 Sweeting $\mathrm{H}$, West $\mathrm{P}$. Health at age 11: reports from schoolchildren and their parents. Arch Dis Childhood 1998; 78:427-34.

46 Passchier J, Orlebeke F. Headaches and stress in schoolchildren: an epidemiological study. Cephalagia 1985; 5:167-76.

47 Scheidt P, Overpeck MD, Wyatt W, Aszmann A. Adolescents' general health and wellbeing. In: Currie C, Hurrelmann K, Settertobulte W, Smith R, Todd J, eds. Health and health behavior among young people. Copenhagen: World Health Organization 2000:24-38.

48 Zencir M, Ergin H, Sahiner T, Kilic I, Alkis E, Ozdel L et al. Epidemiology and symptomatology of migraine among school children: Denizli urban area in Turkey. Headache 2004; 44:780-5.

49 Pothmann R, Frankenberg SV, Müller B, Sartory G, Hellmeier W. Epidemiology of headache in children and adolescents: evidence of high prevalence of migraine among girls under 10. Int J Behav Med 1994; 1:76-89.

50 Sillanpää M, Aro H. Headache in teenagers: comorbidity and prognosis. Funct Neurol 2000; 15:116-21.

51 Sillanpää M. Prevalence of headache in prepuberty. Headache 1983; 23:10-14.

52 Zwart JA, Dyb G, Holmen TL, Stovner LJ, Sand T. The prevalence of migraine and tension-type headaches among adolescents in Norway. The Nord-Trøndelag Health Study (Head-HUNT-Youth), a large populationbased epidemiological study. Cephalalgia 2004; 24:373-9.

53 Bille B. Migraine in childhood: a 30 years follow-up. In: Lanzi G, Balottin U, Cernibori A, eds. Headache in children and adolescents: proceedings of the first international symposium on headache in children and adolescents. Amsterdam: Excerpta Medica 1989:19-26.

54 Al Jumah M, Awada A, Al Azzam S. Headache syndromes amongst schoolchildren in Riyadh, Saudi Arabia. Headache 2002; 42:281-6.

55 Ayatollahi SM, Moradi F, Ayatollahi SA. Prevalences of migraine and tension-type headache in adolescent girls of Shiraz (southern Iran). Headache 2002; 42:287-90.

56 Anttila P, Metsahonkala L, Mikkelsson M, Helenius H, Sillanpaa M. Comorbidity of other pains in schoolchildren with migraine or nonmigrainous headache. J Pediatr 2001; 138:176-80.
57 Laurell K, Larsson B, Mattsson P, Eeg-Olofsson O. A 3 -year follow-up of headache diagnoses and symptoms in Swedish schoolchildren. Cephalalgia 2006; 26:809-15.

58 Anttila P, Metsähonkala L, Sillanpää M. School start and occurrence of headache. Pediatrics 1999; 103:1276.

59 Fearon P, Hotopf M. Relation between headache in childhood and physical and psychiatric symptoms in adulthood: national birth cohort study. BMJ 2001; 322:1-6.

60 Brattberg G. Back pain and headache in Swedish schoolchildren: a longitudinal study. Pain Clin 1993; 6:153-62.

61 Wang S-J, Fuh J-L, Lu S-R, Juang K-D. Outcomes and predictors of chronic daily headache in adolescents. A 2-year longitudinal study. Neurology 2007; 68:591-6.

62 Wanman A, Agerberg G. Recurrent headaches and craniomandibular disorders in adolescents: a longitudinal study. J Craniomandib Disord 1987; 1:229-36.

63 Metsähonkala L, Sillanpää M, Tuominen J. Social environment and headache in 8- to 9-year-old children: a follow-up study. Headache 1998; 38:222-8.

64 Laimi K, Metsähonkala L, Anttila P, Aromaa M, Vahlberg $\mathrm{T}$, Salminen JJ et al. Outcome of headache frequency in adolescence. Cephalalgia 2006; 26:604-12.

65 Laimi K, Vahlberg T, Salminen J, Metsähonkala L, Mikkelsson M, Anttila P et al. Does neck pain determine the outcome of adolescent headache? Cephalalgia 2007; 27:244-53.

66 Monastero R, Camarda C, Pipia C, Camarda R. Prognosis of migraine headaches in adolescents: a 10-year follow-up study. Neurology 2006; 67:1353-6.

67 Virtanen R, Aromaa M, Rautava P, Metsahonkala L, Anttila $\mathrm{P}$, Helenius $\mathrm{H}$ et al. Changing headache from preschool age to puberty. A controlled study. Cephalalgia 2007; 27:294-303.

68 Brna P, Dooley J, Gordon K, Dewan T. The prognosis of childhood headache: a 20-year follow-up. Arch Pediatr Adolesc Med 2005; 159:1157-60.

69 Guidetti V, Galli F, Fabrizi P, Giannantoni AS, Napoli L, Bruni $\mathrm{O}$ et al. Headache and psychiatric comorbidity: clinical aspects and outcome in an 8-year follow-up study. Cephalalgia 1998; 18:455-62.

70 Gladstein J, Holden EW. Chronic daily headache in children and adolescents: a 2-year prospective study. Headache 1996; 36:349-51.

71 Kienbacher C, Wöber C, Zesch HE, Hafferl-Gattermayer A, Posch M, Karwautz A et al. Clinical features, classification and prognosis of migraine and tension-type headache in children and adolescents: a long-term follow-up study. Cephalalgia 2006; 26:820-30.

72 Zebenholzer K, Wöber C, Kienbacher C, Wöber Bingöl C. Migrainous disorder and headache of the tension-type not fulfilling the criteria: a follow-up study in children and adolescents. Cephalalgia 2000; 20:611-16.

73 Metsähonkala L, Sillanpää M, Tuominen J. Outcome of early school-age migraine. Cephalalgia 1997; 17:662-5.

74 Schmidt MH, Blanz B, Esser G. Häufigkeit und Bedeutung des Kopfschmerzes im Kindes- und Jugendalter. Kindheit und Entwicklung 1992; 1:31-5. 